\begin{tabular}{l|r} 
SISTEMA \\
ELETRÔNICO \\
DE REVISTAS \\
SER I UFPR
\end{tabular}

\title{
O litoral da macrometrópole: tão longe de Deus e tão perto do Diabo
}

\section{The coast of the Macro metropolis: so far from God and so close to the Devil}

\author{
Leandra R. GONÇALVES ${ }^{*}$, Luciana Y. XAVIER ${ }^{1}$, Pedro Henrique TORRES ${ }^{2}$, Silvana ZIONI ${ }^{3}$, Pedro R. \\ $\mathrm{JACOBI}^{2}$, Alexander TURRA ${ }^{1}$ \\ ${ }^{1}$ Instituto Oceanográfico, Universidade de São Paulo (USP), São Paulo, SP, Brasil. \\ ${ }^{2}$ Instituto de Energia e Meio Ambiente, Universidade de São Paulo (USP), São Paulo, SP, Brasil. \\ ${ }^{3}$ Programa de Pós-Graduação em Planejamento e Gestão do Território, Universidade Federal do ABC (UFABC), São Paulo, SP, Brasil. \\ *E-mail de contato: leandra.goncalves@usp.br
}

Artigo recebido em 26 de setembro de 2019, versão final aceita em 30 de abril de 2020, publicado em 5 de agosto de 2020.

\begin{abstract}
RESUMO: $\quad$ O maniqueísmo do título deste artigo antecipa o interesse em aqui analisar as particularidades da polarização da zona costeira em uma escala espacial mais abrangente. Tal análise é feita sob a ótica do ordenamento territorial, da abordagem ecossistêmica e da governança ambiental, e considera os fluxos e dinâmicas incidentes sobre a zona costeira em um contexto de desenvolvimento sustentável. Por meio do estudo de caso da Macrometrópole Paulista (MMP), seu Plano de Ação 2013-2040, e as ações propostas para seu litoral, reconhece-se que, tão perto da metrópole expandida, o litoral macrometropolitano segue longe de um caminho sustentável e socialmente justo. Argumenta-se que o planejamento espacial e a governança deste território demandam uma ampla revisão dos paradigmas que amparam os instrumentos setoriais e multissetoriais de gestão. Novos paradigmas devem considerar diferentes escalas espaciais, como a zona costeira, a zona econômica exclusiva e regiões metropolitanas adjacentes. Nesse sentido, faz-se necessário que o planejamento da MMP considere novos arranjos de governança que abarquem a dinamicidade do território e suas dimensões socioambientais e ecossistêmicas. Devem, ainda, incorporar macroprocessos tanto do ponto de vista administrativo e territorial quanto do ponto de vista socioambiental, incluindo os atores apropriados a essa escala e, em especial, garantindo a participação da sociedade civil.
\end{abstract}

Palavras-chave: gestão costeira; planejamento ambiental; estudos regionais; governança ambiental; fluxos socioeconômicos. 
ABSTRACT: The Manichaeism in the title of this anticipates the interest here to analyze the particularities of coastal zone polarization on a broader spatial scale. Territorial planning, ecosystem-based approach, governance, and considering existing flows and dynamics in the context of sustainable development are the bases of this analysis. Using the case study of the São Paulo Macro Metropolis (SPMM), its 2013-2040 Action Plan, and the proposed actions for its coastline as examples, the fact that being so close to the expanding metropolis, the macro metropolitan coastline is far from a socially, fair and sustainable path is verified. Spatial planning and governance of this territory require a broad revision of the paradigms that support sectoral and multisectoral management instruments. This revision should consider different spatial scales, such as the coastal zone, the exclusive economic zone, and adjacent metropolitan regions. In this sense, it is necessary for SPMM planning to consider new governance arrangements that encompass the dynamics of the territory and its socio-environmental dimensions. It is also necessary to incorporate macro-processes from the administrative, territorial, social, and environmental perspectives, including the stakeholders, according to the management scale, and, particularly, ensuring the participation of civil society.

Keywords: coastal management; environmental planning; regional studies; environmental governance; socioeconomic flows.

\section{Introdução}

A crescente metropolização do espaço como uma nova fase de urbanização (Lencioni, 2015; Brenner, 2018), em escalas jamais vistas, e seu deslocamento para áreas adjacentes, inclusive áreas litorâneas, é um fenômeno contemporâneo a ser reconhecido, analisado e incorporado na construção de políticas territoriais e de seus instrumentos de governança (Zioni et al., 2019). As regiões metropolitanas, as megarregiões, as megalópoles, ou outra denominação que se queira dar ao processo urbano contemporâneo em grande escala, são responsáveis por grande parte dos fluxos socioeconômicos do ou para o litoral, e, portanto, por impactos na zona costeira (ZC) (Cunha et al., 2013; Mello et al., 2013).

Historicamente, as áreas costeiras e marinhas favoreceram a concentração da população e aglomerados urbanos, dentre outras razões, por ser ambiente propício à realização de certas atividades tais como: pesca, indústria, turismo e transporte
(Moraes, 2007). Além disso, favoreceram a instalação e implementação de grandes infraestruturas para circulação de mercadorias (Bulleri \& Chapman, 2010). A ZC sustenta indústrias com grande dinamismo como o turismo de veraneio, permite uma apropriação cultural e social que a identifica como espaço de lazer, e ainda salvaguarda espaços preservados, que hoje, são ainda mais valorizados (Moraes, 2007). Todas essas atividades e usos, disputam o território em um ambiente dinâmico e integrado de transição entre o domínio terrestre e marinho.

Por suas características biofísicas, agregando distintos e complexos ecossistemas como praias, restingas, costões rochosos, manguezais, baías e enseadas, a ZC é também responsável por fornecer diversos serviços ecossistêmicos, materiais e imateriais (IPBES, 2018), que conectam esse território, naturalmente propiciando bem-estar e qualidade de vida para as pessoas, e não apenas isso, contribuindo também com o desenvolvimento econômico 
(Moraes, 2007; Scherer \& Asmus, 2016). Os serviços ecossistêmicos costeiros são dependentes de múltiplos processos biofísicos e socioeconômicos cujas escalas espaciais transcendem o nível no qual o serviço é prestado. Garantir a manutenção deles depende tanto da preservação de características essenciais do sistema ecológico, quanto da gestão e ordenamento das atividades do sistema social, tanto no nível em que o serviço é prestado/usufruído, quanto em níveis mais abrangentes, uma vez que a falta de barreiras efetivas nos oceanos conecta todas as suas partes. Tal fato reforça a necessidade de uma abordagem holística e integradora para a gestão (Portman, 2016; Rosenberg \& McLeod, 2005).

Adiciona-se a essa complexidade, a tendência de grande expansão populacional para a zona costeira. Cerca de metade da população mundial vive no litoral, e estima-se que, dentro dos próximos 30 anos, a população costeira dobre, sendo que grande parte desse aumento populacional será nas megacidades costeiras (Li, 2003; Barragán \& Andres, 2015). Essa expansão populacional, ao aumentar os fluxos migratórios e pendulares entre grandes, médias ou pequenas cidades para a zona costeira, seja para colonização, veranismo ou até mesmo pelas oportunidades de trabalho provenientes do crescimento dessas áreas ( $\mathrm{Li}, 2003)$, torna oportuna a reflexão sobre o surgimento de megacidades costeiras (UN, 2016), além do emergencial debate sobre o impacto de uma grande metrópole na zona costeira.

A conexão entre regiões metropolitanas e o litoral a cada dia se torna mais evidente dada a crescente metropolização do espaço (Ribeiro \& Ribeiro, 2010; EMPLASA, 2014; Negreiros et al., 2015; Zioni et al., 2019; Torres et al., 2020), fazendo com que o tema da governança metropolitana abrangendo áreas litorâneas seja retomado tanto no debate acadêmico quanto nas agendas governamentais. Devido à sua complexidade, fluxos e escalas, os territórios metropolitanos e aglomerados urbanos adjacentes demandam políticas transversais e articuladas, envolvendo distintos atores sociais e diferentes níveis de governo, assim como novos arranjos de governança.

O debate sobre o planejamento e a governança de regiões metropolitanas e sobre novos modelos e arranjos institucionais fica ainda mais desafiante ao se considerar a interface sociedade e mar numa perspectiva de sustentabilidade (Ferrol-Schulte $e t$ al., 2013). Com base em trajetórias insustentáveis passadas e com as rápidas mudanças em curso, em níveis locais e planetários (Steffen et al., 2015), torna-se necessária uma transformação inovadora no sistema de governança para a sustentabilidade dos ambientes costeiros e marinhos, e que ainda considere de forma integrada as grandes mudanças globais e locais.

Para ilustrar esse cenário, o recorte da Macrometrópole Paulista (MMP), com destaque em seu litoral, foi escolhido por apresentar, além de original contribuição aos estudos sobre novas escalas espaciais, novos territórios e macrometropolização, uma conjuntura única para discutir a (não) integração da zona costeira a partir de uma relação dialética de interdependência com a metrópole expandida.

$\mathrm{Se}$ as conexões litoral e - metrópole ou as ligações ZC e zona portuária - hinterlândia podem ser vistas como históricos e importantes elementos funcionais de estruturação regional da urbanização paulista, o processo contemporâneo de metropolização do espaço expande a abrangência e intensidade dos elementos e atividades em um território ainda mais ampliado (Torres et al., 2020) e heterogê- 
neos (Travassos et al., 2020). Esse território vem sendo marcado por conflitos regionais e locais significativos (Santos \& Turra, 2017) na proporção dos impactos ambientais sobre seus recursos naturais, de políticas setoriais desconexas e da ausência de governança que articule a diversidade de atores (Torres et al., 2019). Trata-se ainda de uma cartografia forjada de modo a servir à lógica da contemporânea produção capitalista do espaço, no bojo de um processo global de financeirização do território (Klink et al., 2013), em processo que compreende movimentos de re-territorialização e re-escalonamentos (Torres et al., 2020), com acentuado desenvolvimento desigual.

Re-escalonamentos supraurbanos (Brenner, 2018) tem se conectado cada vez mais, criando interdependências socioeconômicas ${ }^{1}$. Por outro lado, as instituições não necessariamente estão acompanhando essa conexão, e são frequentemente fragmentadas em múltiplas agências e departamentos e ainda em multiníveis, por vezes conectados. É nesse sentido que vale reconhecer e analisar a expansão da metropolização do espaço, e discutir formas de governar o território para promover o desenvolvimento sustentável e a redução das desigualdades, de forma dinâmica e que permita transformar e adaptar os sistemas socioecológicos, com responsabilidade e considerando riscos e incertezas relacionados (Veiga, 2014).

Dessa forma, para compreender a relação entre a MMP e sua zona costeira e a forma como está sendo pensada a sua governança, é imperativa uma análise do Plano de Ação da Macrometrópole
Paulista (PAM), documento que consolida a definição do território macrometropolitano e apresenta propostas para sua gestão. O PAM foi conduzido pelo governo do estado de São Paulo entre os anos de 2011 e 2014, e foi publicado em quatro cadernos que constituem o "Plano de Ação da Macrometrópole Paulista - 2013-2040” (PAM) (EMPLASA, 2014). Esse plano busca apontar diretrizes e projetos para serem implementados no território macrometropolitano e estabelece metas até 2040. Assim, o PAM configura-se como um instrumento de visão de Estado e norteador para a elaboração e implementação de políticas públicas ajustadas ao novo espaço e para a proposição de um novo arranjo institucional necessário para a governança da MMP.

Nesse sentido, buscamos realizar uma análise crítica do PAM e sua polarização com a zona costeira em uma escala espacial mais abrangente sob a ótica do ordenamento territorial, da abordagem ecossistêmica e da governança ambiental, considerando seus fluxos e dinâmicas em um contexto de desenvolvimento sustentável.

\section{Abordagem teórica e metodológica}

Para realizar a análise proposta, o universo da Macrometrópole Paulista foi delimitado geograficamente, utilizando a base cartográfica da Empresa Paulista de Planejamento Metropolitano (EMPLASA). Buscou-se ainda, fontes primárias e secundárias sobre os fluxos e serviços ecossistêmicos da região, principalmente oriundas de agências

\footnotetext{
${ }^{1} \mathrm{O}$ fato de estar "conectado" não pressupõe necessariamente a homogeneidade do território. No caso da Macrometrópole Paulista o que se observa, ao contrário, é a característica heterogênea e com "buracos" (Travassos et al., 2020).
} 
governamentais (São Paulo, 2009; EMPLASA, 2014), assim como a conceituação teórica sobre os processos de formação regional e multi-escalar que embasaram a conceituação do que aqui será definido posteriormente como o "litoral da macrometrópole".

Do ponto de vista documental foi realizada uma análise crítica do PAM 2013-2040, em dois de seus volumes. A análise do capítulo sobre governança do volume "Uma visão da macrometrópole", buscou apontar ausências e fragilidades na estratégia para promoção da governança ambiental, do planejamento e do desenvolvimento sustentável, bem como para inclusão de variáveis ambientais, tais como serviços ecossistêmicos providos pela zona costeira. A análise do volume 4, "Carteira de Projetos do PAM", em especial do item "Vetor de Desenvolvimento Caminho do Mar", dedicado exclusivamente à projetos no litoral da MMP, permitiu destacar até que ponto e de que forma o PAM tratou das questões relacionadas à zona costeira e marinha.

A partir do conceito de governança ambiental de Lemos \& Agrawal (2006), buscou-se apresentar contribuições aos atuais desafios sobre os entendimentos em relação aos processos de urbanização em larga escala, com uma abordagem própria a partir do Sul Global (Ribeiro, 2018), demonstrando as especificidades da MMP.

Para Lemos \& Agrawal (2006), governança ambiental compreende uma gestão integrada de programas e políticas públicas, superando o caráter setorial predominante e incluindo uma gama variada de atores governamentais, não-governamentais e privados. Nesse sentido, a governança e as instituições que dela fazem parte configuram-se como fatores determinantes no incremento da capacidade adaptativa e da resiliência de ecossistemas (Duit et al., 2010), componentes e princípios estes que também fazem parte da gestão de base ecossistêmica (Long et al., 2015).

Segundo Lemos \& Agrawal (2006), em vista da complexidade e do caráter multi-escalar de muitos dos problemas ambientais mais prementes, os debates convencionais focados em modos mais tradicionais de governo - onde o Estado ou o setor privado desempenham o papel principal - ficam aquém da capacidade necessária para buscar soluções para os complexos problemas ambientais. Nesse sentido, defendem modos híbridos de governança ambiental que envolvam intrinsecamente: mercado, estado e comunidade.

O surgimento dessas formas híbridas de governança ambiental baseia-se no reconhecimento de que nenhum agente isolado possui as capacidades para abordar as múltiplas facetas, interdependências e escalas de problemas ambientais que podem parecer, à primeira vista, bastante simples. A abordagem híbrida (Lemos \& Agrawal, 2006) apresenta uma natureza multinível e intersetorial e foca não apenas na eficiência e na equidade, mas também em critérios relacionados à sustentabilidade de longo prazo e à preocupação com a natureza e bem-estar humano.

É nesse ponto que a abordagem de governança ambiental aqui utilizada se complementa com a abordagem ecossistêmica que considera principalmente as interações entre os componentes do ecossistema e o manejo, bem como os impactos cumulativos de uma ampla gama de setores e atividades que, de forma direta ou indireta, faz uso dos recursos naturais. Essa abordagem, que já vem sendo difundida há mais de 20 anos (Slocombe, 1993), tem como premissa que os sistemas são socioecológicos e são compostos por elementos 
ecológicos (naturais), econômicos e sociais (Asmus et al., 2018) que se inter-relacionam e se integram.

\section{O litoral da macrometrópole - a expansão urbana e os fluxos metrópole-litoral}

O recorte da Macrometrópole, uma cidade-região para Lencioni (2015), é marcado por aglomerados e assentamentos urbanos e peri-urbanos, modernos ou precários, complexos industriais e de serviços e empreendimentos imobiliários residenciais. Também abriga atividades como o turismo, atividades agrícolas e rurais, áreas naturais, mananciais e uma ampla gama de serviços ecossistêmicos. Configura-se como uma área intensamente integrada por fluxos de bens, mercadorias, pessoas e informações, tendo a capital paulista como seu principal centro polarizador.

A MMP é um dos maiores aglomerados urbanos do Hemisfério Sul (EMPLASA, 2019). Abriga a Região Metropolitana de São Paulo (RMSP) entre as seis maiores do mundo (UN, 2016) - além das regiões metropolitanas da Baixada Santista, Campinas e Sorocaba, o Vale do Paraíba e o Litoral Norte, as Aglomerações Urbanas de Jundiaí e de Piracicaba e a Unidade Regional Bragantina. A MMP cobre uma área de 53,4 mil $\mathrm{km}^{2}$, equivalente a $21,5 \%$ do estado de São Paulo, incluindo 174 municípios e $50 \%$ da área urbanizada de todo o estado (EMPLASA, 2019) (Figura 1).

Esta região concentra os principais portos e aeroportos brasileiros, como o Porto de Santos, os aeroportos de Guarulhos e Viracopos, refinarias e exploração de petróleo e gás, além de um complexo rodoviário e ferroviário, grandes polos de conhecimento, tecnologia e inovação do país (EMPLASA,
2014). A importância socioeconômica da região é traduzida em seus números e evidencia a relevância desse território, no contexto do estado de São Paulo, com quase $75 \%$ da população e sendo responsável por mais de $80 \%$ do PIB do estado (Tabela 1 ).

Ainda que os processos originários de formação dos territórios litorâneos paulistas tenham sido semelhantes - dadas as características locacionais beira-mar, serra, povoados caiçaras, e as relações entre a zonas costeira e o planalto, orientadas a partir de seus principais portos em Santos, São Sebastião e Ubatuba, as duas regiões da Baixada Santista e o Litoral Norte vão se distinguir pelos tempos e ritmos das transformações e de apropriação dos seus espaços.

Enquanto os principais núcleos da Baixada Santista - Santos e São Vicente - serão mais precocemente adensados pelos fortes vínculos aos circuitos do comércio exterior e como vetores de ocupação urbana que demandavam infraestruturas de energia e acesso aos recursos das área do interior polarizados em São Paulo; os portos e povoados do Litoral Norte aguardarão até o século XIX para se conectarem com Salesópolis, Paraibuna e São Luís de Paraitinga e até os anos de 1940 para se interligarem entre si e a São José dos Campos.

Enquanto a Baixada Santista desenvolve um complexo de infraestruturas, atividades industriais e funções turísticas, sua articulação à expansão metropolitana se intensifica, dando lugar a passivos ambientais de grande prejuízo social e econômico; o Litoral Norte se mantém em isolamento, conservando um patrimônio ambiental expressivo, até que nos anos 1980, quando suas ligações com o São Paulo e o Vale do Paraíba são asfaltadas e a exploração turística de veraneio deflagrada, a região passa a ser palco de conflitos socioambientais importantes. 
Para a definição do litoral da MMP é preciso considerar a interdependência da cidade-zona costeira a partir dos fluxos e dinâmicas entre suas principais metrópoles - São Paulo e Campinas e São José dos Campos - que não estão localizadas na zona costeira (Figura 1). De outro lado, a inegável importância de dois complexos portuários no litoral (Santos e São Sebastião) e uma previsão de crescimento de exploração de petróleo e gás na Bacia de Santos - hoje a maior produtora de gás natural e petróleo do Brasil (ANP, 2019) - fazem com que o litoral macrometropolitano, ainda que não tão expressivo em seus indicadores socioeconômicos, receba um destaque por sua importância estratégica para o desenvolvimento econômico. Essa economia em desenvolvimento produzirá grandes mudanças e reforçará a necessidade de uma melhor integração dessa região à metrópole expandida (Lencioni, 2015). Os fluxos e as conexões existentes entre a zona costeira e os polos metropolitanos, revelam dinâmicas diferentes e únicas que ocasionam impactos variados que estimulam uma reflexão sobre os necessários arranjos de governança.

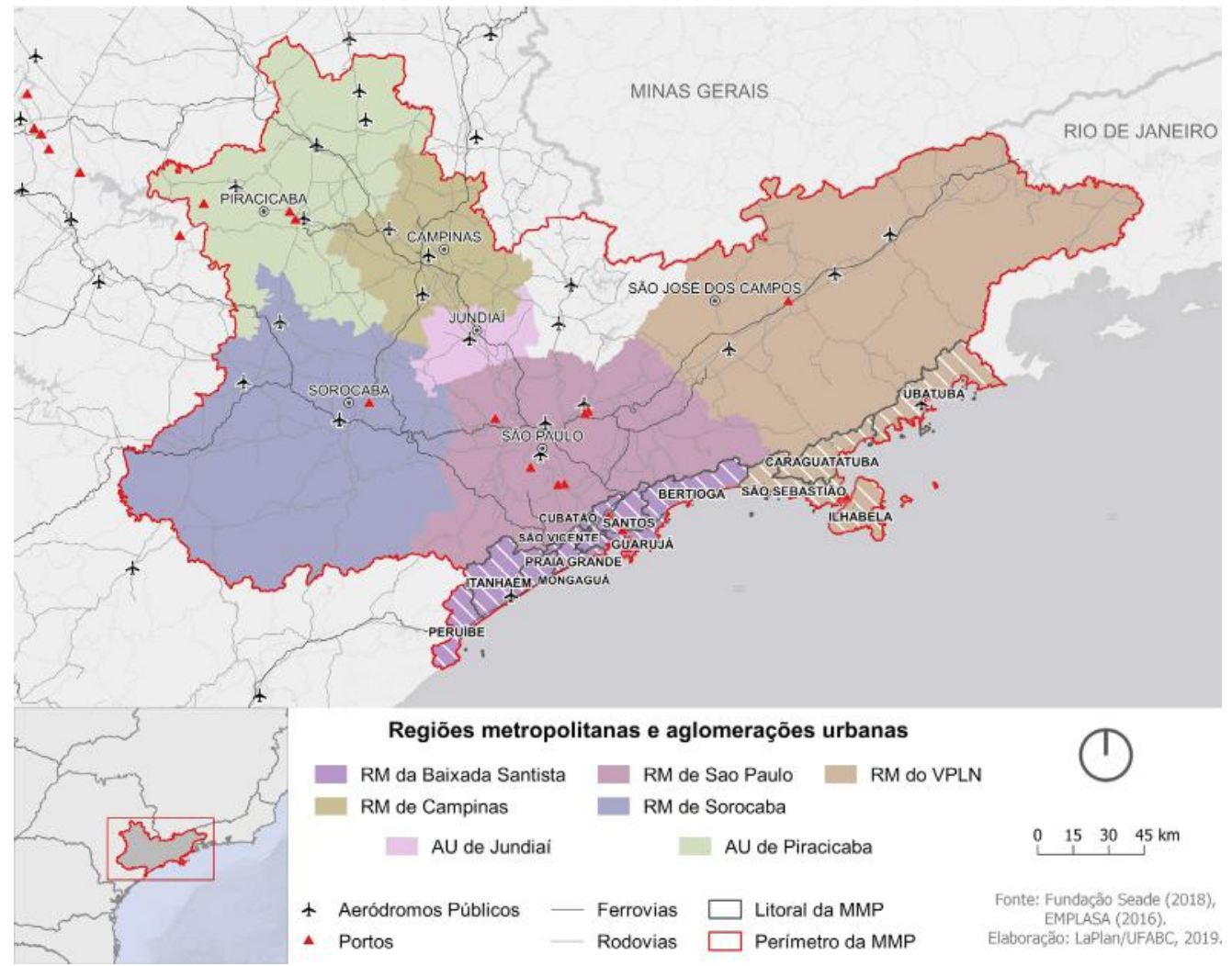

FIGURA 1 - Localização da Macrometrópole Paulista (Brasil, São Paulo) com destaque para o litoral, ressaltando a localização das regiões metropolitanas (RM) e principais infraestruturas (portos, aeroportos, ferrovias e rodovias).

FONTE: Elaborado por LaPlan (UFABC)/FAPESP, 2019. 
TABELA 1 - Indicadores socioeconômicos do território macrometropolitano.

\begin{tabular}{|c|c|c|c|c|c|c|c|c|}
\hline \multirow{2}{*}{$\begin{array}{l}\text { Unidade } \\
\text { territorial }\end{array}$} & \multirow{2}{*}{$\begin{array}{l}\text { N de } \\
\text { Mun. }\end{array}$} & \multicolumn{2}{|c|}{ Área } & \multicolumn{2}{|c|}{ População } & \multirow{2}{*}{$\begin{array}{c}\begin{array}{c}\text { Densidade } \\
\text { Demográfica }\end{array} \\
\text { Hab./km2 } \\
\end{array}$} & \multicolumn{2}{|l|}{ PIB } \\
\hline & & $\mathbf{K m}^{2}$ & $\%$ Estado & Habitantes & \% Estado & & Em mil R\$ & \% Estado \\
\hline RM São Paulo & 39 & $7,946.82$ & 3.20 & $20,935.20$ & 47.54 & $2,634.41$ & $786,499,860.00$ & 55.82 \\
\hline $\begin{array}{l}\text { RM Baixada } \\
\text { Santista }\end{array}$ & 9 & $2,419.93$ & 0.97 & $1,781,620.00$ & 4.05 & 736.23 & $60,076,046.00$ & 4.26 \\
\hline RM Campinas & 20 & $3,791.91$ & 1.53 & $3,055,996.00$ & 6.94 & 805.93 & $110,229,437.00$ & 7.82 \\
\hline$R M V P L N$ & 39 & $16,192.71$ & 6.52 & $2,430,392.00$ & 5.52 & 150.09 & $65,644,358.00$ & 4.66 \\
\hline RM Sorocaba & 26 & $9,821.22$ & 3.96 & $1,867,260.00$ & 4.24 & 190.13 & $48,745,342.00$ & 3.46 \\
\hline $\begin{array}{l}\text { UR Bragan- } \\
\text { tina }\end{array}$ & 10 & $2,768.03$ & 1.12 & $410,456.00$ & 0.93 & 148.28 & $8,264,838.00$ & 0.59 \\
\hline $\begin{array}{l}\text { Litoral da } \\
\text { MMP }\end{array}$ & 13 & $4,377.81$ & 1.76 & $2,217,578.00$ & 1.10 & 506.55 & $\mathrm{n} / \mathrm{a}$ & $\mathrm{n} / \mathrm{a}$ \\
\hline$M M P$ & 173 & $51,577.99$ & 20.78 & $32,669,687.00$ & 74.19 & 633.40 & $1,161,625,628.00$ & 82.45 \\
\hline Estado de SP & 645 & $248,222.36$ & $\mathrm{n} / \mathrm{a}$ & $202,033,670.00$ & $\mathrm{n} / \mathrm{a}$ & 177.40 & $1,408,903,870.00$ & $\mathrm{n} / \mathrm{a}$ \\
\hline
\end{tabular}

FONTE: Elaborado pelos autores com dados da EMPLASA (2014), IBGE (2019).

O litoral da Macrometrópole Paulista (Figura 2), está compreendido em duas regiões Metropolitanas: a Região Metropolitana da Baixada Santista (RMBS) e a do Vale do Paraíba e Litoral Norte (RMVPLN). Ambas relevantes por sua importância ambiental e por serem polos atrativos de turismo e de atividades econômicas. Dos 39 municípios da RMVPLN, quatro estão no litoral, são eles Caraguatatuba, Ilhabela, São Sebastião e Ubatuba. Dos nove municípios da RMBS, oito municípios estão localizados na zona costeira: Bertioga, Guarujá, Itanhaém, Mongaguá, Peruíbe, Praia
Grande, Santos e São Vicente. Embora Cubatão não seja um munícipio defronte ao mar, ele vem sendo considerado um município costeiro nas instâncias de planejamento urbano estadual e federal (MMA, 2020; São Paulo, 2020), e, portanto, será aqui considerado como parte do litoral da macrometrópole, sobretudo por sua importância socioeconômica, com um dos maiores PIBs per capitas do litoral macrometropolitano (Tabela 2).

O litoral da MMP tem, portanto, 13 municípios, e corresponde a 2,74\% do Estado de São Paulo. Entre o litoral existem municípios com alta densi- 
dade demográfica, como Guarujá, Praia Grande e São Vicente - todos os três localizados na Baixada Santista. E outros como Ilhabela, com baixa densidade demográfica relativa, porém apresentando o maior PIB do litoral norte paulista (Tabela 2).

Esta proporção litorânea abrange uma ampla diversidade de ecossistemas no Bioma da Mata Atlântica, incluindo estuários, manguezais, restingas, rios, costões rochosos, praias arenosas e dezenas de ilhas (Santos \& Turra, 2017; Menezes et al., 2005). Estes ambientes são responsáveis pela provisão de diversos serviços ecossistêmicos com grande importância social e econômica (alimento, proteção da linha de costa, turismo, lazer etc.) (Carrilho \& Sinisgalli, 2018; Amaral et al., 2016) e vêm sofrendo o impacto das mudanças climáticas, do crescimento populacional e da ocupação desordenada (MMA, 2014; Santos \& Turra, 2017; Teixeira, 2013).

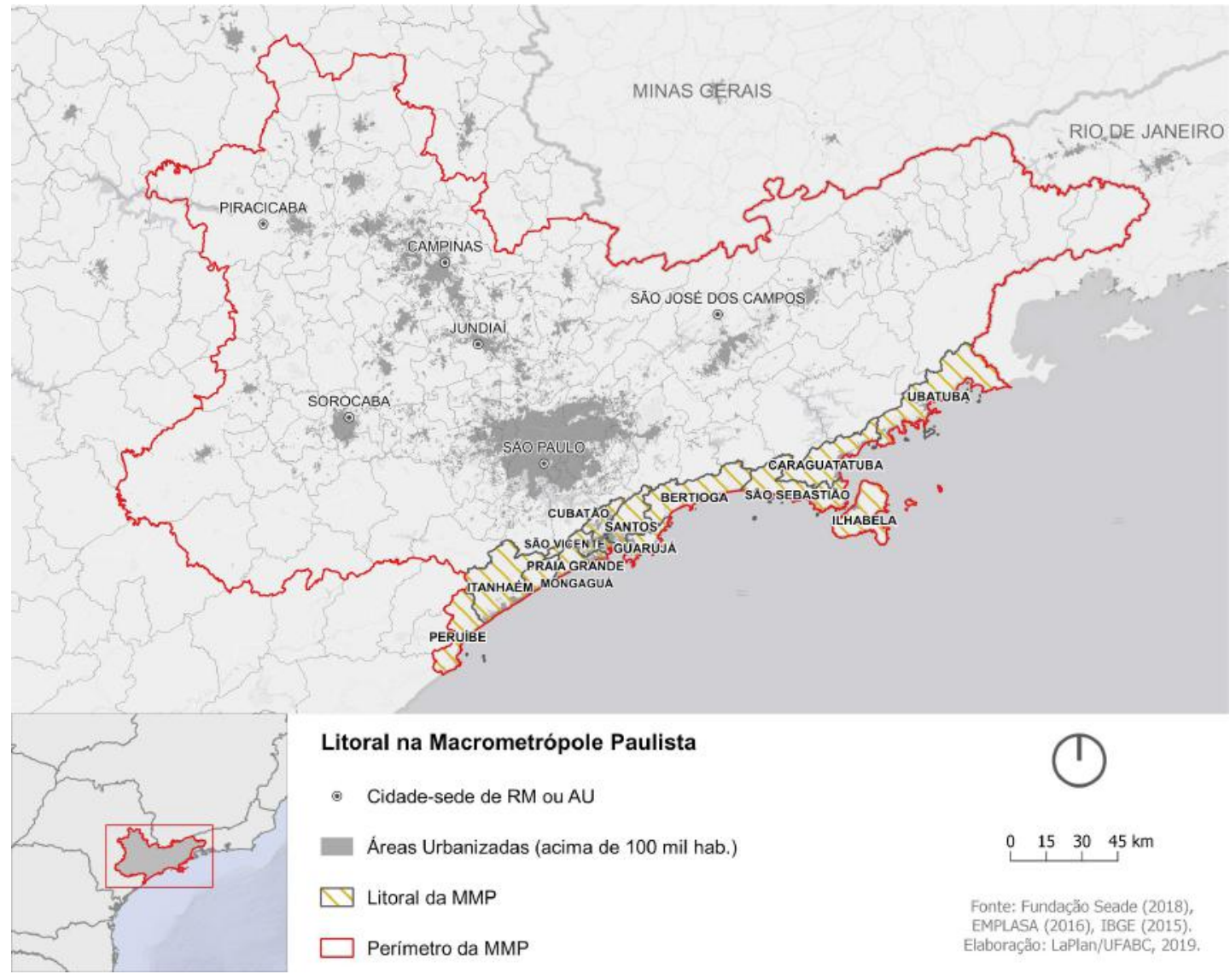

FIGURA 2 - Destaque ao litoral macrometropolitano (Estado de São Paulo, Brasil) e a proximidade com áreas urbanizadas. FONTE: Elaborado por LaPlan (UFABC)/FAPESP, 2019. 
TABELA 2 - Indicadores socioeconômicos da RMVPLN e RMBS com destaque para o litoral macrometropolitano.

Área População $\begin{array}{r}\text { Densidade } \\ \text { demográfica }\end{array}$

Unidade Territorial

\begin{tabular}{|c|c|c|c|c|c|c|}
\hline & $\begin{array}{l}\text { Área } \\
\left(\mathbf{k m}^{2}\right)\end{array}$ & $\%$ (Estado) & Habit. & $\%$ (Estado) & $\mathbf{H a b} / \mathbf{k m}^{2}$ & (reais) \\
\hline Caraguatatuba & 485.01 & 0.20 & 121,532 & 0.06 & 250.58 & $23,100.59$ \\
\hline São Sebastião & 399.68 & 0.16 & 73,942 & 0.04 & 185.00 & $41,724.54$ \\
\hline Ubatuba & 723.83 & 0.29 & 90,799 & 0.04 & 125.44 & $20,447.30$ \\
\hline Bertioga & 490.15 & 0.20 & 63,249 & 0.03 & 129.04 & $25,674.73$ \\
\hline Guarujá & 142.59 & 0.06 & 380,527 & 0.19 & $2,668.70$ & $25,224.38$ \\
\hline Itanhaém & 599.02 & 0.24 & 100,496 & 0.05 & 167.77 & $16,454.23$ \\
\hline Mongaguá & 143.21 & 0.06 & 55,731 & 0.03 & 389.17 & $17,115.56$ \\
\hline Peruíbe & 326.21 & 0.13 & 67,548 & 0.03 & 207.07 & $18,066.20$ \\
\hline Cubatão & 142.28 & 0.06 & 118,720 & 0.06 & 834.41 & $138,153.22$ \\
\hline Litoral da MMP & $6,799.61$ & 2.74 & $4,116,686.00$ & 2.04 & 605.43 & $\mathrm{n} / \mathrm{a}$ \\
\hline
\end{tabular}

PIB per capita (reais)

FONTE: Elaborado pelos autores com informações do IBGE (2019). 
A Região Metropolitana da Baixada Santista (RMBS) foi criada em 1996 e é integrada por nove municípios: Bertioga, Cubatão, Guarujá, Itanhaém, Mongaguá, Peruíbe, Praia Grande, Santos e São Vicente.

A RMBS caracteriza-se pela diversidade de funções de seus municípios. Além do parque industrial de Cubatão e do Complexo Portuário de Santos, a região desempenha funções de destaque em nível estadual, nos setores industrial e de turismo, e outras de abrangência regional, relativas aos comércios atacadista e varejista, ao atendimento à saúde, educação, transporte, sistema financeiro e de suporte ao comércio de exportação (EMPLASA, 2019).

A RMBS possui uma estrutura industrial dinâmica, cujos segmentos mais expressivos são o refino de petróleo e a metalurgia básica, além do ramo químico. A importância desses setores é complementada por inúmeras plantas industriais de bens intermediários. As indústrias de fabricação de alimentos e bebidas também são atividades importantes. Em Cubatão, concentra-se o complexo químico-siderúrgico formado pelo polo petroquímico, desenvolvido ao redor da Refinaria Presidente Bernardes, da Petrobrás, de indústrias de fertilizantes e químicas, e a Companhia Siderúrgica Paulista - Cosipa (São Paulo, 2012).

O Porto de Santos também agrega importância para a região e foi responsável por cerca de $28,5 \%$ do movimento de exportações e importações portuárias do país em 2016 (EMPLASA, 2019). O Plano Mestre do Porto de Santos (Brasil, 2018) indica que haverá crescimento na movimentação das cargas de 1,6\% ao ano, com 280,1 milhões de toneladas de sal, farelo de soja, produtos siderúrgicos, contêineres, produtos químicos, trigo, milho, celulose, entre outros produtos. Mais que o dobro da quantidade operada em 2018, que foi de 133,1 milhões de toneladas. No cenário pessimista do Plano, que prevê aumento de $1,2 \%$ anuais, o Porto em 2060, movimentará 233,5 milhões de toneladas (Brasil, 2018).

Para o estado de São Paulo, a presença e ampliação do Porto de Santos é estratégica e representa potencial rearranjo distributivo de bens de consumo, permitindo o direcionamento de grande parcela de suas atividades industriais e agrícolas para o suprimento de mercados internos e internacionais. Com a descoberta, na Bacia de Santos, de jazidas petrolíferas no chamado "pré-sal", existe a perspectiva de grande aumento da exploração de petróleo e gás na região, assim como o crescimento significativo da demanda para os setores industriais e de serviços (Brasil, 2018).

Por sua vez, outra porção do litoral paulista, o Litoral Norte, integra a Região Metropolitana do Vale do Paraíba e Litoral Norte (RMVPLN). Esta região, criada em 2012 é integrada por 39 municípios, configurando cinco sub-regiões, entre as quais o Litoral Norte paulista (LNP). Essa é composta pelos municípios de Ubatuba, Caraguatatuba, Ilhabela e São Sebastião (Fundação SEADE, 2020). A taxa de crescimento anual da população, de $1,58 \%$ ao ano, tem diminuído, porém ainda é bastante superior à média estadual de $0,80 \%$ ao ano (Fundação SEADE, 2020). Esse aumento populacional, associado ao crescimento urbano da região está diretamente atrelado ao desenvolvimento do turismo e às atividades industriais que vêm sendo implementadas na região e atraindo muitos trabalhadores (Teixeira, 2013). Sua velocidade, no entanto, vem sendo superior à velocidade dos agentes públicos locais em planejar e promover ações coordenadas para combater os impactos derivados da falta de planejamento de forma 
coordenada (Santos \& Turra, 2017). Dessa forma, problemas relacionados a um deficiente sistema de saneamento básico, de destinação de resíduos, de ocupação de áreas irregulares e poluição e degradação da zona costeira e seus recursos vêm sendo agravados anualmente.

Com referência às atividades industriais do LNP, além dos projetos da indústria de petróleo e gás, destacam-se o projeto de ampliação da capacidade de movimentação de cargas no Porto de São Sebastião e a consequente adaptação de toda a logística rodoviária regional, incluindo a ampliação da capacidade de tráfego da Rodovia SP-099 (Teixeira, 2013).

Com os altos preços internacionais do petróleo, que chegou a US\$ 130 até a crise de internacional de $2008^{2}$, a exploração e produção de petróleo e gás na Bacia de Santos, no pré-sal ou pós-sal, teve impactos significativos na economia paulista (São Paulo, 2009). Na Baixada Santista, por exemplo, houve uma ampliação da demanda para os setores industriais e de serviços (São Paulo, 2009). Assim, grandes empresas de óleo e gás, bem como fabricantes de equipamentos para refinarias, embarcações e sondas, se instalaram na região, provocando um novo fluxo migratório para a zona costeira que acrescentou, desde 2007, cerca de $1.8 \%$ ao ano, em média, à população existente (São Paulo, 2009).

No caso da RMBS os cenários de projeção futura indicam aumento da população em todos os municípios, subindo de 1.749 .343 para 1.957 .612 habitantes, com aumentos expressivos para as cidades de Bertioga, Cubatão, Mongaguá e Praia Grande (São Paulo, 2009). Ainda que sejam apenas cenários, não diferem muito do debate proposto por Meyer na ocasião do dossiê da Revista Iberoamericana de Urbanismo que argumenta que o recorte metropolitano paulista enfrenta "uma rápida reestruturação produtiva" (Meyer, 2015, p. 2) e que estamos diante de um "território em movimento, cujas características físicas e funcionais deverão nortear os projetos urbanos a serem desenvolvidos para atender as demandas inscritas nesta nova escala urbana cotidiana" (Meyer, 2015, p. 4). Ainda, de acordo com Meyer, a evolução da mancha urbana seguiu, ao longo dos anos, da metrópole para o interior e litoral, sendo esse desenvolvimento incentivado pela construção da malha viária metropolitana (Meyer et al., 2015). Mas não apenas isso. A relação planalto-litoral fez parte da gênese da metrópole devido ao escoamento do café (Moraes, 2007) em tempos que antecedem essa intensa metropolização do espaço.

Vale mencionar ainda que a MMP é marcada pela pobreza e desigualdade, com inúmeros assentamentos precários de um lado, e condomínios fechados do outro (Marques et al., 2013; Travassos et al., 2019). Nota-se que em 2010 cerca de 3.8 milhões de habitantes viviam em assentamentos precários em uma área de 31,5 mil km² na RMSP (Marques et al., 2013). O mesmo estudo aponta que a RMSP é a que tem o maior número de pessoas residentes em domicílios particulares permanentes em setores subnormais (2.169.502 pessoas) e em setores precários (652.318), seguido da RMBS, com 297.091 habitantes em setores subnormais, e a Região Metropolitana de Campinas (RMC), com 234.273 moradores em setores precários (Marques et al., 2013). 
Além disso, a dinâmica da MMP é marcada pela pendularidade intermetropolitana e macrometropolitana e com alto contraste entre índices econômicos positivos e baixos índices de desenvolvimento social (Negreiros et al., 2015). A Baixada Santista é um caso emblemático, onde nota-se "riqueza à beira-mar e pobreza longe da maresia" (Jakob et al., 2006, p. 25) e um apanhado de problemas de desigualdade, em decorrência da sua ocupação metropolitana (Young \& Santos, 2008).

A proximidade à metrópole e a ocupação urbana desordenada também trazem consequências para o litoral paulista, dentre elas o acentuamento de desigualdades sociais (Young \& Fusco, 2005), pressão direta nos serviços públicos, como saneamento básico, coleta de resíduos, disponibilidade de água e entre outros, que não são adequados à demanda, principalmente em períodos de veraneio, colocam a saúde pública em risco e evidenciam a fragilidade do litoral frente às demandas metropolitanas (CBH, 2018).

Esse movimento populacional ressalta as necessidades de políticas habitacionais para a zona costeira, o que demanda planejar o território de forma integrada, considerando que os impactos setoriais precisam ser analisados em uma abordagem integrada de políticas públicas que considere os diferentes níveis e escalas de planejamento (Cash et al., 2006).

Esses fluxos populacionais e os impactos decorrentes reforçam a importância de se rever os paradigmas atuais de governança no território macrometropolitano, não apenas por seu recorte político-institucional, mas porque, assim como pontuado por Lencioni (2015, p. 13), "vivemos menos numa cidade e mais numa região", e é por meio desses inúmeros fluxos que essa cidade-região se conecta com a zona costeira. Pela mesma lógica, esse território também se conecta com a zona marinha ou oceânica. $\mathrm{O}$ mar territorial, e também a porção da zona econômica exclusiva correspondente à Bacia de Santos, guarda relações intrínsecas com a macrometrópole que necessitam ser incorporadas ao entendimento de sua dinâmica e de sua governança.

Nas palavras de Lencioni (2015, p.13), fazendo referência ao litoral de Rio de Janeiro e São Paulo, "é como se essa megarregião brasileira tivesse um espelho a refletir sua imagem no mar", pois afinal, há uma fronteira tênue a ser observada entre a parte continental (costeira) e o mar adjacente, onde se sobrepõe diversas atividades. Inclui-se desde o turismo com grandes navios de cruzeiros até mesmo a exploração de petróleo em águas profundas, que produziu e produzirá, em um futuro próximo, diversas modificações na economia macrometropolitana, sobretudo na zona costeira, em consequência de novas obras e infraestruturas, chegada de trabalhadores especializados e novos mercados e serviços (Lencioni, 2015). Estima-se que a maior parte das demandas por infraestrutura ocorrerão ao longo do litoral paulista, destacadamente entre os municípios de Itanhaém e Caraguatatuba (CESPEG, 2011).

Nota-se, portanto, que a zona costeira, e sua porção marinha adjacente, a Zona Econômica Exclusiva (ZEE), funciona como um provedor de bens e serviços, porém, ainda se encontra apenas marginalmente integrada à parte continental por meio do PAM. Nesse sentido, tão próxima da metrópole para ofertar serviços, porém tão distante de um desenvolvimento sustentável e repleta de impactos, agravos e conflitos. 


\section{O Plano de Ação da Macrometrópole Paulista para o Litoral}

O Plano de Ação da Macrometrópole Paulista tem o objetivo de "definir as diretrizes e orientar a ação pública no território macrometropolitano para lhe garantir competitividade econômica e desenvolvimento sustentável" (EMPLASA, 2014, Vol. 2, p. 30). Assim, é importante analisar como ele considera a dinâmica mar, costa e metrópole e prevê ações voltadas à integração territorial por meio de estratégias de governança, sobretudo a partir da análise de seu volume Vetor de Desenvolvimento "Caminhos do Mar". O PAM definiu a MMP com 172 municípios, muito similar à sua configuração atual, com 174 municípios (EMPLASA, 2019), tomando como principais diretrizes a constituição de uma região competitiva e inovadora. De acordo com Tavares (2018), buscou-se com o PAM uma macrometrópole una, diversa, policêntrica, compacta e viva. Nas palavras do governador do estado de São Paulo à época "Os limites físicos e políticos desses espaços não são mais suficientes para caracterizá-los. É necessário compreendê-los como redes - a base da contemporaneidade na realização de sua vida socioeconômica" (EMPLASA, 2014, p. 3).

De fato, o PAM é o único documento que trata da MMP. E ainda que não pretenda ser um formulador de políticas, parte de alguns pressupostos - redução do protagonismo do estado, restrição de recursos financeiros, interesse do mercado na exploração de recursos naturais - que certamente implicariam formas de governança específicas. Entretanto ele apenas se propõe a revelar uma carteira de projetos e formas de gestão e não discute ou apresenta a governança sobre o território macrometropolitano.

A partir dos quatro volumes do PAM, nota-se uma orientação desenvolvimentista, embora o discurso da sustentabilidade esteja presente, senão como eixos, vetores e projetos, como narrativa. A visão prevalecente é de integrar o território para desenvolver almejando crescimento econômico. Como se com a integração das metrópoles e aglomerados urbanos, fosse possível extrair o que há de mais promissor em cada território para o desenvolvimento econômico. A sensação é compartilhada por Tavares (2018) que destaca a ausência de ações planejadoras e "o desafio de destacar a MMP de suas amarras históricas que a prendem à lógica industrial de base fordista (monocêntrica, hierarquizada e dividida funcionalmente) e transpô-la para o novo debate do desenvolvimento da reterritorialização produtiva". Essa análise também ecoa com o posto por Araújo et al. (2020) que argumenta que o PAM apresenta sustentabilidade apenas procedimental, com medidas paliativas, porém não levando em conta critérios importantes para a promoção da sustentabilidade urbana. Os mesmos autores ainda afirmam que o PAM é pautado principalmente pela apropriação econômica dos bens naturais, e sem buscar reduzir as assimetrias socioambientais.

Em diversas passagens são exploradas as oportunidades para o desenvolvimento:

Fatores importantes demonstram o grande potencial de crescimento dessa região, ainda pouco aproveitado ou prejudicado em face dos gargalos de natureza logística, que têm os Portos de Santos e do Rio de Janeiro como principais saídas de sua produção, dados o ainda reduzido tamanho e a baixa utilização do Porto de São Sebastião (EMPLASA, 2014, p. 59). 
Os fluxos também são reconhecidos no território, como nota-se pela passagem, em que se discute a demanda por recursos hídricos:

As evidências disponíveis demonstram que está em curso na Macrometrópole um forte processo de descentralização das funções residenciais e produtivas, criando estruturas urbanas em múltiplas escalas - urbana, metropolitana e macrometropolitana. São esses processos de intensa dispersão de funções urbanas que engendram novas centralidades, organizadas por redes de fluxos e relações (EMPLASA, 2014, p. 28).

A importância dos serviços ecossistêmicos é reconhecida, embora tenha sido subdimensionada a sua relevância para a justiça, o bem-estar e qualidade de vida. Em geral, a menção desse conceito é feita de forma a garantir a manutenção do "ativo ambiental" para propiciar o desenvolvimento econômico (EMPLASA, 2014, Vol. 2, p. 31) e ou para promover uma política de Pagamentos por Serviços Ambientais (EMPLASA, 2014, p. 91). Nota-se que os serviços ecossistêmicos não são considerados dentro da dimensão socioambiental, e nem mesmo como ativos na promoção de um desenvolvimento mais sustentável para o território. Tampouco os serviços ecossistêmicos são considerados numa perspectiva mais holística da abordagem ecossistêmica, trazendo processos de manejo adaptativo, sustentabilidade e conexão entre o ambiente natural e a sociedade.

Vale mencionar que outros serviços ecossistêmicos fornecidos pela zona costeira não foram considerados e nem sequer mencionados nos volumes analisados do PAM, tais como a provisão de alimentos (por ex: a pesca marinha de grande e pequena escala), energia a partir da dinâmica oceânica, ou a regulação climática (afora a política prevista na Política Estadual de Mudanças Climáticas - PEMC) entre outros serviços ecossistêmicos imateriais (IPBES, 2018).

Existe um reconhecimento da necessidade de integração do território e de políticas intersetoriais, da importância do diálogo multinível e policêntrico, presente na Visão Estratégica do PAM de formular políticas públicas integradas para o território da MMP envolver os demais níveis de governo, o setor privado e a sociedade na proposição e implementação das ações e de projetos metropolitanos (EMPLASA, 2014, p. 10). Porém, para o caso da ZC, não é feito um levantamento das políticas existentes, como Plano Estadual de Gerenciamento Costeiro de São Paulo (Lei No 10.019, de 03 de Julho de 1998), ou o Zoneamento Ecológico Econômico Costeiro (Decreto Estadual 49.215, em 7 de Dezembro de 2004), e de como elas serão influenciadas ou integradas no contexto da implementação do PAM. O plano não dá atribuições e tampouco indicações de como os atores irão se relacionar nesse contexto. Nesse sentido, o PAM, no que tange a ZC, perde força, figurando mais como uma carta de intenções e de potenciais projetos, mas sem inovar em proposições de governança para esse novo recorte territorial.

A região da Baixada Santista, assim como do Litoral Norte Paulista também são subestimados nos Cenários do PAM. Sua menção é sempre relacionada à expansão portuária e a necessidade de criar infraestrutura para ao escoamento de gás e óleo. Entretanto, o Litoral Norte, no contexto da região metropolitana do Vale do Paraíba, tem também outras vocações (Santos \& Turra, 2017) que sequer foram mencionadas no PAM, como sua importância para manifestações culturais, pesca e cultura caiçara. 
No volume 1 do PAM, as possibilidades para o desenvolvimento do Litoral Norte são descritas como "incipientes, embora possam vir a ser dinamizadas em função dos investimentos previstos para a logística e operação da extração de petróleo e gás natural nos campos do pré-sal" (EMPLASA, 2014 , p. 223). No volume 4 do PAM, a carteira de projetos, a promoção do Turismo Sustentável ganha prioridade 6 , nos 13 vetores de prioridade para o desenvolvimento da Região Metropolitana do Vale do Paraíba e Litoral Norte, porém, as ações não receberam a mesma prioridade ${ }^{3}$ dos demais projetos de desenvolvimento (Tavares, 2016).

Nota-se que o PAM é de fato pioneiro não apenas em relação à escala de planejamento (Tavares, 2018), mas também na tentativa de estabelecer ações descentralizadas, ensaiando uma governança policêntrica, multinível e intersetorial. Porém, o PAM falha do ponto de vista da inovação na dimensão da governança ambiental e da aplicação de uma gestão baseada em ecossistemas ao não reconhecer os recursos naturais da região como essenciais ao próprio projeto de desenvolvimento proposto. Não há, na Carteira de Projetos do PAM, destaque para as áreas prioritárias de conservação da macrometrópole paulista, essenciais, por exemplo, para manutenção de serviços básicos como abastecimento de água, recuperação dos estoques pesqueiros e proteção da biodiversidade, e um dos principais ativos ambientais do Litoral Norte.

$\mathrm{Na}$ cartografia oficial da Macrometrópole, tendo como referência a soma dos 174 municípios, estão ausentes, por exemplo, as Unidades de Conservação costeiras e marinhas do estado de São
Paulo, evidenciando grave lacuna em termos de planejamento e governança ambiental deste território. Ao não considerar com integrante de sua fronteira a faixa litorânea e o mar territorial como parte integrante da Macrometrópole, não há previsão sobre a governança desse espaço e de seus recursos. Tampouco há uma análise dos possíveis efeitos dos projetos propostos sobre o ecossistema natural do território costeiro, incluindo informações sobre como as obras propostas podem afetar os hotspots para conservação da biodiversidade na Macrometrópole Paulista. O PAM falha e perde a oportunidade de inovar ao não priorizar o entendimento de variabilidade climática e a necessidade imperativa de que os novos projetos de infraestrutura levem em consideração tais cenários, com maior capacidade adaptativa e de resiliência.

No Eixo de Desenvolvimento "Caminho do Mar" estão listados 11 vetores (EMPLASA, 2014, p. 123), classificados por prioridade. Todos eles estão relacionados à logística e infraestrutura, como, por exemplo, o Veículo Leve sobre Trilhos (VLT) da Baixada Santista, a implantação de Plataforma Logísticas Periféricas junto ao ferroanel e o túnel Santos - Guarujá. Não há menção a questão de impactos, compensação e ou adaptação às mudanças climáticas nessas construções na zona costeira.

Nesse sentido, se por um lado os exemplos acima citados e presentes no Eixo Caminho do Mar recuperam projetos e eixos presentes em outros planos, como no Plano Metropolitano de Desenvolvimento Estratégico da Baixada Santista (São Paulo, 2014) e projetos previstos em parceria com outros níveis de governo, como prefeituras e

\footnotetext{
${ }^{3}$ O Plano de Ação da Macrometrópole (Emplasa, 2014) sugere ordem de priorização das obras, projetos e eixo para se alcançar os objetivos previstos no volume Visão do Estado
} 
governo federal, representando assim a desejável busca por políticas multinível e intersetoriais, por outro lado não faz o necessário diálogo com outros atores para avançar do ponto de vista da inovação, da governança ambiental e da GBE, no envolvimento das políticas ambientais, seja o Zoneamento Ecológico Econômico ou Plano Estadual de Gerenciamento Costeiro.

Toda essa problemática e os processos socioespaciais são abordados nos quatro cadernos do Plano de Ação da Macrometrópole Paulista (PAM-20132040). Porém, as diretrizes de desenvolvimento apresentam lacunas socioambientais. No caso específico dos portos, por exemplo, não há menção ou qualquer avaliação sobre os impactos ambientais que novos portos ou a ampliação dos existentes trariam para a região (EMPLASA, 2014, p. 51-53).

Embora seja reconhecida sua importância como documento orientador, o PAM pouco avança na fundamental discussão sobre como promover a gestão do território, de forma a integrar as políticas existentes e criar inovações onde identifica lacunas. Tampouco inova em romper com o paradigma de que desenvolvimento econômico e desenvolvimento sustentável podem ser complementares na promoção da governança ambiental desse novo território.

E, nesse sentido, outro ponto chave que merece destaque em relação à governança da Macrometrópole Paulista, a partir do PAM, é a dificuldade de sua implementação. Com baixa participação da sociedade civil durante a elaboração do plano (Xavier \& Torres, 2019) e os desafios do próprio governo do estado em definir a composição do Grupo de Trabalho de implementação e monitoramento, sua implementação segue de maneira desarticulada. A aplicação, por exemplo, de instrumentos da GBE poderia suprir essa lacuna, ao incorporar novos processos socioecológicos e mais atores à gestão, mas também encontra-se incipiente no plano.

Torna-se assim, fundamental construir processos mais abrangentes, holísticos e participativos de planejamento e gestão integrada visando a promoção do uso racional e da conservação das áreas e recursos naturais costeiros e marinhos, bem como da manutenção dos processos e características dos ecossistemas presentes, considerando o impacto de uma grande região metropolitana, sob a ótica do desenvolvimento sustentável. Isto implica, necessariamente, na conciliação de aspectos socioambientais em consonância com os anseios da sociedade. O PAM, ainda que com um reconhecido esforço técnico, construiu suas bases voltado principalmente para as relações público-privadas, marginalizando as relações do privado com o social. Deixou de lado importante capital social na relação público-comunitário. Assim, o PAM ainda precisa avançar na promoção do desenvolvimento sustentável do território, tal como definido em Veiga (2014), e na articulação dos demais atores, em busca de uma governança híbrida, como previsto no conceito de governança ambiental de Lemos \& Agrawal (2006). Ainda, carece reconhecer o território macrometropolitano como um sistema socioecológico, que inclui a intrínseca relação entre o homem e a natureza, no contexto da abordagem ecossistêmica (Figura 3).

Pela análise da carteira de projetos, nota-se que as parcerias público-privadas são voltadas principalmente aos eixos desenvolvimentistas (e.g. Portos, Rodovias e exploração de combustíveis fósseis), as parcerias sócio-privadas ao pagamento de serviços ambientais, e por sua vez, a gestão participativa, envolvendo comunidades costeiras, e demais atores 
sociais, carece de um espaço nessa nova escala de planejamento.

\section{Desafios para a governança macro metropolitana ambiental}

O desafio de atender às necessidades humanas, os fluxos econômicos e a produção material de um mundo em urbanização em escala planetária e a tensão que o atual modelo de desenvolvimento impõe à promoção do desenvolvimento sustentável, confronta cientistas, tecnólogos, tomadores de decisão e comunidades em todos os níveis, do local ao global, e apresenta desafios para o debate e a prática da governança ambiental.
A governança ambiental tem uma história recente no Brasil e que ganhou força a partir da Constituição de 1988 quando, junto com a entrada no período democrático, foi instituído um novo sistema de gestão descentralizado (Moraes, 2007; Abrucio \& Sydow, 2018) e a possibilidade do envolvimento de diferentes atores na tomada de decisão - governo, empresariado e a sociedade civil. Porém, a descentralização também veio acompanhada de um quadro político-administrativo de grande setorização, levando a conflitos entre os diferentes instrumentos de gestão das diferentes políticas públicas incidentes sobre temas ambientais. Apesar de mais de 30 anos de sistema descentralizado, as estruturas hierárquicas de poder ainda não se transformaram de forma a permitir uma maior fluidez do poder político (Abrucio \& Sydow, 2018), e nem

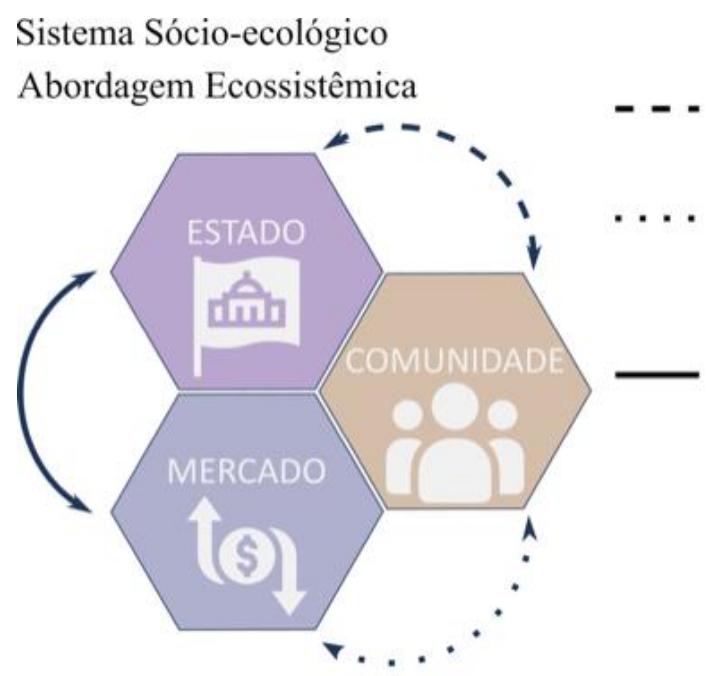

\section{Gestão participativa de recursos naturais \\ Parceria sócio-privada \\ Pagamento por serviços ambientais}

\section{Parceria público-privada}

Construção de portos, rodovias, VLT Baixada Santista, túnel SantosGuarujá; implantação de Plataformas Logísticas Periféricas.

FIGURA 3 - Mecanismos e estratégias de governança ambiental.

FONTE: Elaborado pelos autores e adaptado de Lemos \& Agrawal (2006). 
mesmo o compartilhamento de responsabilidades com demais atores, ampliando a participação social (Wever et al., 2012).

A governança da MMP é complexa, onde podem se destacar diversos modais (ferroviário, marítimo e rodoviário), diretrizes altamente setorizadas como os planos municipais de resíduos, de recursos hídricos, para a zona costeira, de mobilidade e ainda de mudanças climáticas. Há também um conjunto diversificado de atores sociais, desde organizações não governamentais (ONGs) ambientais, movimentos sociais e ambientais, até influentes setores privados, comunidades costeiras e tradicionais, pescadores e pescadoras e movimentos sociais (Wever et al., 2012; Santos \& Turra, 2017; Stori et al., 2019; Torres et al., 2019).

Adicionado a esse complexo sistema que já enfrenta diversos conflitos em decorrência dos usos múltiplos, as zonas costeiras são as áreas de maior risco no mundo e serão as porções mais afetadas pelas mudanças ambientais globais (Nicholls et al., 2016). Entre os diversos efeitos dessas mudanças globais pode se destacar aqueles associados ao aumento do nível médio do mar e a maior frequência e intensidade de eventos climáticos extremos (IPCC, 2014). Por estar dentro da faixa tropical e sob influência direta do domínio climático Tropical Atlântico, a costa paulista tende a sofrer mais intensamente os episódios climáticos e ambientais que irão se manifestar na forma de riscos e perigos específicos, como erosão marinha e salinização dos deltas de rios (Marques, 2010).

No ambiente marinho, os impactos das mudanças climáticas afetam diretamente processos e características físico-químicas. Consequentemente, além dos perigos relatados acima, terão efeitos negativos na provisão dos serviços ecossistêmicos que dependem desses fatores. Assim, o processo de governança ambiental deve buscar incluir os componentes de governança ambiental explicitados por Lemos \& Agrawal em 2006, assim como um olhar mais integrado e ecossistêmico, abarcando princípios como participação social, resiliência, manejo adaptativo e sustentabilidade.

Considerando a intensificação de atividades produtivas, a mudança do uso e do ordenamento territorial do litoral de São Paulo, a degradação ambiental e os impactos das mudanças climáticas, nota-se que as iniciativas empreendidas pelas instituições públicas visando uma gestão mais efetiva e participativa têm se mostrado ineficazes diante dos impactos existentes (Santos \& Turra, 2017; Stori et al., 2019). Essa situação gera controvérsias na tomada de decisão e contestação das soluções trazidas pelas políticas públicas, planos e programas. É nesse contexto que o planejamento e a governança de cidades costeiras precisam ser considerados, merecendo atenção especial dada sua complexidade, volume e magnitude de fluxos, pressões e atividades conflitantes, atuando conjuntamente com a dificuldade em compatibilizar uso e conservação de seus bens e serviços ecossistêmicos.

Nesse sentido, vale complementar o conceito de governança ambiental, aos princípios da gestão de base ecossistêmica (GBE) (Long et al., 2015). A GBE, não será aprofundada neste artigo, mas é uma forma de gestão de recursos naturais que vem se destacando ao longo das últimas décadas (Slocombe, 1993). Nasceu da percepção de que a forma tradicional de planejamento e manejo de recursos naturais não mais eram suficientes para resolver os complexos problemas ambientais, e que era necessário inovar por meio de um olhar mais abrangente, que considerasse os sistemas socioecológicos, e 
trouxesse uma abordagem mais integrada, não apenas entre os seres humanos e meio ambiente, mas também entre os diversos níveis de gestão (vertical e horizontal). Ou seja, a aplicação desse conceito na gestão territorial da macrometrópole pode contribuir para contemplar os serviços ecossistêmicos, e a sustentabilidade, integrando as diversas escalas político-administrativas.

Cabe enfatizar que pensar na gestão dos serviços ecossistêmicos dentro e fora das grandes cidades vem se tornando cada vez mais necessário para aumentar a perspectiva de melhoria do bem-estar das populações associadas a estes conglomerados. Este tema é ainda subestimado nas diretrizes do PAM. Porém, é nesse contexto e no âmbito de um sistema socioecológico complexo que o planejamento e a governança de cidades costeiras precisam ser considerados, merecendo atenção especial dada sua complexidade, volume e magnitude de fluxos e pressões e atividades conflitantes, atuando conjuntamente com a dificuldade em compatibilizar uso e conservação de seus bens e serviços ecossistêmicos.

O território macrometropolitano apresenta desafios quanto à dimensão de seu território expandido. E as soluções, que precisam ser inovadoras, passam pela articulação, integração e cooperação dos agentes envolvidos. Ainda dada a característica transversal e multi-escalar, a necessária governança se realiza pela busca da redução de conflitos e harmonização de interesses, demandando robusta integração de políticas.

Os desafios são complexos, porém, não se pode furtar de incluir a dimensão socioambiental no contexto da governança macrometropolitana, aspecto não abordado com profundidade necessária no PAM e que poderia agregar inovação ao processo. Ainda, observa-se que muitos atores sociais foram subestimados no PAM, e pouco envolvidos no processo de construção, principalmente os habitantes das zonas costeiras. A incorporação da dimensão socioambiental ao processo de gestão das políticas públicas na gestão costeira envolve a discussão de múltiplos aspectos, o que requer a incorporação de novos conceitos e métodos, nos quais as políticas, processos, práticas e programas se tornam partes integrantes da lógica de governança. Assim, além da responsabilidade social, se incorpora a dimensão da sustentabilidade como promotora de ações pautadas pela inovação e criatividade, sendo que comunicação e estratégias criativas e inovadoras de diálogo comunitário serão cada vez mais importantes. Nota-se pela análise do PAM que foram priorizados mecanismos de governança voltados ao incentivo apenas do desenvolvimento econômico, deixando as questões ambientais marginalmente exploradas e não promovendo um desenvolvimento territorial sustentável, especialmente da região costeira e marinha.

Dada a complexidade do território macrometropolitano e sua interface com o litoral, qualquer projeto institucional proposto precisaria funcionar bem em ambientes sociais e ecológicos muito diferentes para lidar efetivamente com uma variada gama de desafios. Embora possa parecer óbvio que a capacidade adaptativa deva ser um dos componentes desse sistema de governança, esses critérios não são enfatizados no PAM.

A urbanização, por sua vez, apresenta-se como uma janela crítica de oportunidades para catalisar soluções - para gerar futuros urbanos e globais mais sustentáveis e inclusivos por meio de transformações sociais, infraestruturais e econômicas (Wigginton et al., 2016). A sustentabilidade de cidades costeiras depende da inclusão social e de 
sua manutenção, do bem-estar econômico e da qualidade ambiental dentro das cidades, minimizando os impactos externos negativos sem gerar passivos para o futuro. Trata-se de refletir sobre uma nova forma de abordar a governança e o planejamento urbano que traz desafios à gestão costeira, dada a magnitude da MMP. Sem paralelos mundo afora, do ponto de vista de sua institucionalidade, magnitude e desenho geográfico (Tavares, 2018), a MMP traz aspectos necessários de serem contemplados nas futuras discussões com os diversos atores envolvidos com o gerenciamento costeiro do estado de São Paulo.

A análise do PAM revelou que ainda hoje prevalece nas diretrizes de desenvolvimento da MMP, um modelo centrado na atração de investimentos com grandes impactos ambientais, remoção de famílias, poluição atmosférica, portos, complexos siderúrgicos, complexos industriais, redução de áreas de prioritárias para o desenvolvimento ou o incentivo à exploração do combustível fóssil sem previsão de sua transição para uma desenvolvimento sustentável. Nota-se também o marginal envolvimento de demais atores sociais, e a priorização da parceria público-privada.

Ainda, nota-se que no caso da macrometrópole paulista, faz-se necessária uma abordagem que inclua não apenas a parte continental do território, mas também considere os fluxos e usos existentes na zona costeira e marinha (mar territorial e ZEE), visando inovar na governança ambiental multinível, e ampliar a governança dessa cidade-região para também aquilo que corresponde a lâmina d'água, mas ainda assim intrinsecamente conectado ao ter- ritório urbano. Atividades como a pesca, industrial e artesanal, turismo e lazer, e ainda os serviços ecossistêmicos de ordem imaterial foram subestimados ou desconsiderados na abordagem do PAM. Entretanto, esses possuem papel significativo na promoção do bem-estar humano (Joly et al., 2019). A questão das mudanças climáticas é abordada de forma tangencial e subdimensionada, porém seus efeitos podem, inclusive, impactar os planos e a carteira de projetos previstos no PAM que, como já afirmam Araújo et al. (2020), é pautado pelo investimento e incentivo do modal rodoviário ${ }^{4}$ - uma contradição quando se busca a transição para uma economia de baixo carbono.

A governança multinível tem potencial para ser uma promissora abordagem em recortes territoriais complexos, e dinâmicos como a MMP. Porém, essa arena é ainda conflituosa, onde os interesses, e por consequência as práticas espaciais, encontram-se sobrepostas e sob a gestão de diferentes autarquias, além de não necessariamente estarem incorporando a dimensão socioambiental.

\section{Conclusã̃o}

Conceituamos neste artigo o que entendemos por litoral da Macrometrópole Paulista, território que compreende a parte costeira da Região Metropolitana do Vale do Paraíba e o Litoral Norte Paulista (RMVPLN) e a Região Metropolitana da Baixada Santista (RMBS), relevante pela sua importância ambiental e por ser um polo atrativo de turismo e de desenvolvimento econômico. $\mathrm{O}$

\footnotetext{
${ }^{4}$ Dissertação de Mestrado (PGT/UFABC) de Gomes (2018) é importante e original contribuição em relação ao Plano de Ação da Macrometrópole e a priorização do Estado em relação ao setor de transporte e logística.
} 
litoral macrometropolitano, como demonstrado, é extremamente conectado à metrópole paulista por meio dos fluxos socioeconômicos e serviços ecossistêmicos, porém, essa conexão ainda não merece destaque na principal política orientadora do território da MMP - o PAM.

A direção estratégica apontada pelo PAM indica a predominância de um modelo que trata a questão do desenvolvimento sustentável de forma marginal, e frágil articulação com a variada gama de atores sociais presentes nesse território, deixando de lado a oportunidade de avançar rumo a uma governança ambiental, inclusiva e que aborde o território com um olhar ecossistêmico.

Devido à sua complexidade, fluxos e escalas, a MMP demanda políticas transversais e articuladas, envolvendo distintos agentes do desenvolvimento e diferentes níveis de governo. Também é necessário que o planejamento da MMP considere o mar territorial e a zona econômica exclusiva como uma extensão macrometropolitana, o que demanda, novos arranjos de governança que abarquem a dinamicidade do território e incorporem macroprocessos tanto do ponto de vista administrativo e territorial quanto do ponto de vista socioambiental.

Nota-se ainda, que a governança multinível e policêntrica é uma condição necessária, mas não suficiente, para responder a questões complexas multiescalares e multissetoriais para a governança macrometropolitana. A coordenação e a integração de estratégias para gestão territorial, manejo de recursos entre jurisdições e setores de políticas são as tarefas mais significativas e desafiadoras para a governança ambiental da MMP. Cabe frisar, mais uma vez, que boa parte dos projetos e das ações da carteira de projetos pressupõe uma governança que vai além da esfera estadual, envolvendo os governos federal e municipal, a iniciativa privada, bem como o controle da sociedade.

Espera-se com essa reflexão promover também uma agenda de pesquisa voltada à interface entre metrópoles e zonas costeiras em locais de intensa metropolização, e que esse debate possa incentivar e estimular o desafio da sustentabilidade costeira e metropolitana em um contexto de governança ambiental transescalar e por meio de uma abordagem ecossistêmica. Recuperando a melancólica imagem de Porfírio Diaz em relação a dicotomia espaço-temporal entre México e Estados Unidos, o Litoral da Macrometrópole, segue distante das benesses prometidas pelo desenvolvimento e segue cada vez mais perto do colapso socioambiental.

\section{Agradecimentos}

Os(as) autores(as) agradecem o apoio da Fundação de Amparo à Pesquisa do estado de São Paulo (FAPESP) (LRG: 2018/00462-8 e 2019/044810; LYX: 2017/21797-5 e 2019/13851-5; PHCT: 2018/06685-9 e 2019/05644-0). O trabalho é parte das atividades do projeto temático, em andamento, "Governança ambiental na Macrometrópole Paulista, face à variabilidade climática", processo $\mathrm{n}^{\circ}$ 2015/03804-9, financiado pela FAPESP e vinculado ao Programa FAPESP de Pesquisa sobre Mudanças Climáticas Globais.

\section{Referências}

Abrucio, F. L.; Sydow, C. T. Federalismo e governança multinível em regiões metropolitanas: o caso brasileiro. In: Carneiro, J. M. B.; Frey, K. (Org.). Governança multinível e desenvolvimento regional sustentável. Experiências do 
Brasil e da Alemanha. São Paulo: Oficina Municipal, 2018. p. 47-68.

Amaral, A. C. Z.; Corte, G. N.; Rosa Filho, J. S.; Denadai, M. R.; Colling, L. A.; Borzone, C. A.; Veloso, V.; Omena, E. P.; Zalmon, I.; Rocha-barreira, C. A.; Souza, J. R. B.; Rosa, L. C.; Almeida, T. C. M. Brazilian Sandy Beaches: Characteristics, ecosystem services, impacts, knowledge and priorities. Brazilian Journal of Oceanography, 64, 5-16, 2016.

ANP - Agência Nacional do Petróleo. Bacia de Santos. Sumário Geológico e Setores em Oferta. Superintendência de Definição de Blocos SDB. Disponível em: <http://rodadas. anp.gov.br/arquivos/Bienio/Mapas_R16/Sumario_Geologico_R16_Santos.pdf>.Acesso em: set. 2019.

Araújo, G. P.; Rodrigues, L. S.; Dunder, B. D.; Zanirato, S. H. Planejamento e sustentabilidade urbana: uma análise do Plano de Ação da Macrometrópole Paulista. Revista Brasileira de Meio Ambiente, 8(1), 100-112, 2020.

Asmus, M. L.; Nicolodi, J.; Scherer, M. E. G.; Gianuca, K.; Costa, J. C.; Goersch, L.; da Rosa Pereira, C. Simples para ser útil: base ecossistêmica para o gerenciamento costeiro. Desenvolvimento e Meio Ambiente, 44, 4-19, 2018.

Barragán, J. M.; de Andrés, M. Analysis and trends of the world's coastal cities and agglomerations. Ocean \& Coastal Management, 114, 11-20, 2015.

Brasil. Plano Mestre do Porto de Santos. Brasília: Ministério da Infraestrutura, 2018.

Brenner, N. Espaços da urbanização: o urbano a partir da teoria crítica. Rio de Janeiro: Letra Capital: Observatório das Metrópoles, 2018.

Bulleri, F.; Chapman, M. G. The introduction of coastal infrastructure as a driver of change in marine environments. Journal of Applied Ecology, 47(1), 26-35, 2010.

Carrilho, C. D.; Sinisgalli, P. A. Contribution to Araçá Bay management: The identification and valuation of ecosystem services. Ocean \& coastal management, 164, 128-135, 2018.

Cash, D. W.; Adger, W. N.; Berkes, F.; Garden, P.; Lebel, L.; Olsson, P.; Young, O. Scale and cross-scale dynamics: governance and information in a multilevel world. Ecology and society, 11(2), 1-12, 2006.

$\mathrm{CBH}$ - Comitê de Bacias Hidrográficas. Relatório de situação dos recursos hídricos do litoral norte. Ano 2018. Dados 2017. Disponível em: < http://www.sigrh.sp.gov.br/ public/uploads/documents//CBH-LN/13809/relatorio_situacao_2018_ugrhi03.pdf $>$ Acesso em: jul. 2020.

CESPEG - Comissão Especial De Petróleo E Gás Natural Do Estado De São Paulo. Relatório de atividades 2008. São Paulo: CESPEG, 2011.

Cunha, J. M. P. da; Stoco, S.; Dota, E. M.; Negreiros, R.; Miranda, Z. A. I. de. A mobilidade pendular na Macrometrópole Paulista: diferenciação e complementaridade socioespacial. Cadernos Metrópole, 15(30), 433-459, 2013.

Duit, A.; Galaz, V.; Eckerberg, K.; Ebbesson, J. Governance, complexity, and resilience. Global Environmental Change, 20(3), 363-36, 2010.

EMPLASA - Empresa de planejamento do Governo do Estado de São Paulo. Plano de Ação da Macrometrópole Paulista 2013-2040: cenários e desafios da macrometrópole. São Paulo: Secretaria da Casa Civil, 2014.

EMPLASA - Empresa de planejamento do Governo do Estado de São Paulo. Macrometrópole paulista. Disponível em: <https://www.emplasa.sp.gov.br/MMP>. Acesso em: jul. 2019.

Ferrol-Schulte, D.; Wolff, M.; Ferse, S.; Glaser, M. Sustainable Livelihoods Approach in tropical coastal and marine social-ecological systems: A review. Marine Policy, 42, 253-258, 2013.

Fundação SEADE. Perfil dos Municípios Paulistas. Disponível em: <https://perfil.seade.gov.br/\#>. Acesso em: fev. 2020.

Gomes, T. Von Z. Macrometrópole Paulista: formação de uma agenda seletiva de venda de uma região - caso dos projetos de transporte. Santo André, Dissertação (Mestrado em Planejamento e Gestão do Território) - UFABC, 2018.

IBGE - Instituto Brasileiro de Geografia e Estatística. Estimativas da população residente para os municípios e para as unidades da federação brasileiros com data de referência em $1^{\circ}$ de julho de 2017: [notas metodológicas], 2017. Disponível em: < https://biblioteca.ibge.gov.br/visualizacao/ 
livros/liv100923.pdf> Acesso em: jul. 2020.

IBGE - Instituto Brasileiro de Geografia e Estatística. Cidades. Disponível em: <https://cidades.ibge.gov.br>. Acesso em: jul. 2019.

IPBES - Intergovernmental Science-Policy Platform on Biodiversity and Ecosystem Services. Summary for policymakers of the global assessment report on biodiversity and ecosystem services of the Intergovernmental Science-Policy Platform on Biodiversity and Ecosystem Services. S. Díaz; J. Settele; E. S. Brondizio; E.S., H. T. Ngo, M; Guèze; J. Agard; A. Arneth; P. Balvanera; K. A. Brauman, S. H. M. Butchart, K. M. A. Chan, L. A. Garibaldi, K. Ichii, J. Liu, S. M. Subramanian, G. F. Midgley, P. Miloslavich, Z. Molnár, D. Obura, A. Pfaff, S. Polasky, A. Purvis, J. Razzaque, B. Reyers, R. Roy Chowdhury, Y. J. Shin, I. J. Visseren-Hamakers, K. J. Willis, and C. N. Zayas (Eds.). Bonn, Germany: IPBES secretariat, 2018. Disponível em: $<$ https://www.ipbes.net/global-assessment-report-biodiversity-ecosystem-services>. Acesso em: ago. 2019.

IPCC - Intergovernmental Panel on Climate Change. Climate Change 2014: Synthesis Report. Contribution of Working Groups I, II and III to the Fifth Assessment Report of the Intergovernmental Panel on Climate Change. Pachauri, R.K.; Meyer, L.A. (eds.). Geneva: IPCC, 2014.

Jakob, A. A. E.; Cunha, J. M. P da; Young, A. F. Riqueza a beira-mar, pobreza longe da maresia: um retrato da segregação social na Região Metropolitana da Baixada Santista, nos anos 1990. In: Cunha, J. M. P. da (Org.). Novas Metrópoles Paulistas - população, vulnerabilidade e segregação. Campinas: NEPO/UNICAMP, v.1., 2006. p. 435-455.

Joly, C. A.; Scarano, F. R.; Bustamante, M.; Gadda, T. M. C.; Metzger, J. P. W.; Seixas, C. S.; Ometto, J. P.; Pires, A. P. F.; Boesing, A. L.; Sousa, F. D. R.; Quintão, J. M. B.; Gonçalves, L. R. G.; Padgurshi, M. C. G.; Aquino, M. F. S.; Santos, I. L. D. Brazilian assessment on biodiversity and ecosystem services: summary for policy makers. Biota Neotropica, 19(4), 1-8, 2019.

Klink, J.; Oliveira, V.; Zimerman, A. Neither spatial Keynesianism, nor competitive neolocalism: rescaling and restructuring the developmental state and the production of space in Brazil. International Journal of Urban Sustainable Development, 5(1), 25-39, 2013.
Lemos, M. C.; Agrawal, A. Environmental governance. Annual Review of Environment and Resources, 31, 297 325, 2006.

Lencioni, S. Urbanização difusa e a constituição de megarregiões: o caso de São Paulo-Rio de Janeiro. E-metropolis, 22(6), 6-15, 2015.

Li, H. Management of coastal mega-cities - a new challenge in the 21st century. Marine Policy, 27(4), 333-337, 2003.

Long, R. D.; Charles, A.; Stephenson, R. L. Key principles of marine ecosystem-based management. Marine Policy, 57, 53-60, 2015.

Marques, C. População e riscos às mudanças ambientais em zonas costeiras da Baixada Santista: um estudo sócio-demográfico sobre os municípios de Bertioga, Guarujá e São Vicente. Dissertação (Mestrado em Demografia) UNICAMP, 2010.

Marques, E.; Bittar, M.; Cazolato, D.; Fusaro, E.; Waldvogel, D. Diagnóstico dos assentamentos precários nos municípios da Macrometrópole Paulista. São Paulo: CEM, 2013.

Mello, K.; Toppa, R. H.; Abessa, D. M. de S.; Castro, M. Dinâmica da expansão urbana na zona costeira brasileira: o caso do município de São Vicente, São Paulo, Brasil. Revista de Gestão Costeira Integrada, 13(4), 527-539, 2013.

Menezes, G. V.; Schaeffer-Novelli, Y.; Poffo, I. R. F.; Eysink, G. G. J. Recuperação de manguezais: um estudo de caso na Baixada Santista de São Paulo, Brasil. Brazilian Journal of Aquatic Science and Technology, 9(1), 67-74, 2005.

Meyer, R. M. P. São Paulo e seus territórios urbanos contemporâneos. Revista Iberoamericana de Urbanismo, 12, $1-6,2015$.

Meyer, R. M. P.; Galvão, R. F. P.; Longo, M. R. São Paulo e suas escalas de urbanização: cidade, metrópole e macrometrópole. Revista Iberoamericana de Urbanismo, 12, 7-31, 2015.

MMA - Ministério do Meio Ambiente. Os 25 Anos Do Gerenciamento Costeiro No Brasil: Plano Nacional De Gerenciamento Costeiro (Pngc). Brasília: MMA/SRH/ GI-GERCO, 2014.

MMA - Ministério do Meio Ambiente. Municípios Costei- 
ros. Disponível em: <https://www.mma.gov.br/destaques/ item/10602-são-paulo-munic\%C3\%ADpios-da-zona-costeira.html;\%20https://www.infraestruturameioambiente. sp.gov.br/cpla/zoneamento/zoneamento-ecologico-economico/baixada-santista/>. Acesso em: jul. 2020.

Moraes, A. C. R. Contribuições para a gestão da zona costeira do Brasil: elementos para uma geografia do litoral brasileiro. v. 47. São Paulo: Annablume, 2007.

Negreiros, R.; Santos, S. M. M. D.; Miranda, Z. A. I. D. Nova escala de planejamento, investimento e governança: na macrometrópole paulista. Revista Iberoamericana de Urbanismo, 12, 121-135, 2015.

Nicholls, R. J.; Woodroffe, C.; Burkett, V. Coastline degradation as an indicator of global change. In: Letcher, T. M. (Ed.). Climate Change. Amsterdã: Elsevier. 2016. p. 309-324.

Portman, M. E. Environmental Planning for Oceans and Coasts. Switzerland: Springer, 2016.

Ribeiro, L. C. de Q. A escala metropolitana no contexto da metrópole liberal-periférica latino-americana. In: Brandão, C. A.; Fernández, V. R.; Ribeiro, L. C de Q. (Orgs.). Escalas espaciais, reescalonamento e estatalidades: lições e desafios para América latina. Rio de Janeiro: Letra Capital; Observatório das Metrópoles, 2018.

Ribeiro, L. C.; Ribeiro, M. G. Metropolização e as estruturas produtivas: convergências e divergências espaço-temporais. Cadernos Metrópole, 12(24), 331-347, 2010.

Rosenberg A. A.; McLeod K. L. Implementing ecosystem-based approaches to management for the conservation of ecosystem services. Marine Ecology Progress Series, 300, 270-274, 2005.

Santos, C. R.; Turra, A. (Orgs.). Rumos da sustentabilidade costeira: uma visão do Litoral Norte Paulista. São Paulo: Instituto Oceanográfico da Universidade de São Paulo, 2017.

São Paulo. Secretaria do Meio Ambiente. Coordenadoria de Planejamento Ambiental. Carvalho, C. R. R. L.; Rosenberg, R. (Coords.). Projeto Ambiental Estratégico Cenários Ambientais 2020. São Paulo: SMA/CPLA, 2009.

São Paulo. Relatório de atividades. Agência Metropoli- tana da Baixada Santista, 2012. Disponível em: $<$ http:// www.agem.sp.gov.br/midia/Relatorio-de-Atividades-AGEM2012.pdf> Acesso em: set 2019.

São Paulo. Plano Metropolitano de Desenvolvimento Estratégico da Baixada Santista. 2014-2030. Agência Metropolitana da Baixada Santista, 2014. Disponível em: $<$ https://www.agem.sp.gov.br/wp-content/uploads/2019/10/ AGEM-PMDE-CADERNO_compressed.pdf $>$. Acesso em jul. 2020.

São Paulo. Secretaria do Meio Ambiente. Coordenadoria de Planejamento Ambiental. Zoneamento Ecológico Econômico. Baixada Santista. Disponível em: $<$ https://www. infraestruturameioambiente.sp.gov.br/cpla/zoneamento/ zoneamento-ecologico-economico/baixada-santista/> Acesso em: jul. 2020.

Scherer, M. E.; Asmus, M. L. Ecosystem-based knowledge and management as a tool for integrated coastal and ocean management: A Brazilian initiative. Journal of Coastal Research, 75(sp1), 690-695, 2016.

Slocombe D. S. Implementing Ecosystem-Based Management. Bioscience, 43, 612-622, 1993.

Steffen, W.; Richardson, K.; Rockström, J.; Cornell, S. E.; Fetzer, I.; Bennett, E. M.; Biggs, R.; Carpenter, S. R.; Vries, W.; Folke, C.; Gerten, D.; Heinke, J.; Mace, G. M.; Persson, L. M.; Ramathan, V.; Reyers, B.; Sorlin, S. Planetary boundaries: Guiding human development on a changing planet. Science, 347(6223), 1259855, 2015.

Stori, F. T.; Shinoda, D. C.; Turra, A. Sewing a blue patchwork: An analysis of marine policies implementation in the Southeast of Brazil. Ocean \& coastal management, 168, 322-339, 2019.

Tavares, J. Eixos: novo paradigma do planejamento regional? Os eixos de infraestrutura nos PPA's nacionais, na Iirsa e na macrometrópole paulista. Cadernos Metrópole, 18(37), 671-695, 2016.

Tavares, J. Formação da macrometrópole no Brasil: Construção teórica e conceitual de uma região de planejamento. EURE (Santiago), 44(133), 115-134, 2018.

Teixeira, L. R. Megaprojetos no litoral norte paulista: o papel dos grandes empreendimentos de infraestrutura na 
transformação regional. Campinas, Tese (Doutorado em Ciências Ambientais) - UNICAMP, 2013.

Torres, P. H. C.; Ramos, R. F.; Gonçalves, L. R. Conflitos ambientais na Macrometrópole Paulista: Paranapiacaba e São Sebastião. Ambiente \& Sociedade, 23, 1-21, 2019.

Torres, P. H. C.; Ramos, R. F.; Pollachi, A. A Macro metropolização em São Paulo: Reterritorialização, reescalonamento e a cidade-região. Cadernos Metrópole, 47, 103-122, 2020.

Travassos, L.; Momm, S.; Torres, P. H. C. Apontamentos sobre urbanização, adaptação e vulnerabilidades na Macrometrópole Paulista. In: Torres, P.; Jacobi, P.; Barbi, F.; Gonçalves, L. R. Governança e Planejamento Ambiental: Adaptação e políticas públicas na Macrometrópole Paulista. Rio de Janeiro: Letra Capital, 2019. p. 120-126.

Travassos, L.; Zioni, S.; Torres, P. H. C.; Fernandes, B.; Araújo, G. Heterogeneidade e fragmentação espacial na Macrometrópole paulista: a produção de fronteiras e buracos. Ambiente \& Sociedade, 23, 1-22, 2020.

UN - United Nations. Department of Economic and Social Affairs, Population Division. The World's Cities in 2016. Data Booklet (ST/ESA/ SER.A/392), 2016. Disponível em: < https://www.un.org/en/development/desa/population/ publications/pdf/urbanization/the_worlds_cities_in_2016_ data_booklet.pdf $>$ Acesso em: jul. 2020

Veiga, J. E. D. O âmago da sustentabilidade. Estudos Avançados, 28(82), 7-23, 2014.
Xavier, L. Y.; Torres, P. H. C. A participação popular na construção da Macrometrópole Paulista. Diálogos Sustentáveis da Macrometrópole Paulista, 3, 8-12, 2019.

Wever, L.; Glaser, M.; Gorris, P.; Ferrol-Schulte, D. Decentralization and participation in integrated coastal management: Policy lessons from Brazil and Indonesia. Ocean \& coastal management, 66, 63-72, 2012.

Wigginton, N. S.; Fahrenkamp-Uppenbrink, J.; Wible, B.; Malakoff, D. Cities are the future. Science, 352, 904-905, 2016.

Young, A. F.; dos Santos, A. P. R. Desigualdade social, dinâmica populacional e meio ambiente: uma abordagem sobre o processo de urbanização da Região Metropolitana da Baixada Santista. In: Anais do XVI Encontro Nacional de Estudos Populacionais, Caxambu- MG, 29 de set., 2008.

Young, A. F.; Fusco, W. Espaços de Vulnerabilidade Socioambiental para a população da Baixada Santista: Identificação e análise das áreas críticas. In: Anais do XV Encontro Nacional de Estudos Populacionais, Caxambu-MG, 18 de set., 2005.

Zioni, S.; Travassos, L.; Momm, S.; Leonel, A. A Macrometrópole Paulista e os desafios para o planejamento e gestão territorial. In: Torres, P.; Jacobi, P.; Barbi, F.; Gonçalves, L. R. Governança e planejamento ambiental: adaptação e políticas públicas na macrometrópole paulista. Rio de Janeiro: Letra Capital, 2019. 